REVIEW

\title{
THE ROLE OF THE NATIONAL SCIENCE FOUNDATION IN PROMOTING BIOLOGICAL SCIENCES RESEARCH
}

\author{
MANTHRI S. RAMASAMY ${ }^{1^{*}}$ and ROHINI WIJAYARATNE ${ }^{2}$ \\ ${ }^{1}$ Institute of Fundamental Studies, Kandy \\ ${ }^{2}$ National Science Foundation, 47/5 Maitland Place Colombo 7
}

(Received : 05 May 1999 ; accepted : 03 September 1999 )

\begin{abstract}
With the establishment of the National Science Council (NSC) in 1968, systematic research in biological sciences supported by public funds was initiated in the country. Funding from the NSC and its successors has been pivotal in providing opportunities for research in biological sciences in the universities and other research institutes. The awards of research grants have heen based on current research priorities and the merits of grant applications determined by the NSC and its successors. The allocation for individual grants has increased in rupee terms over the 30 year period from 1968. However, the publication of research in good quality scientific journals has heen unsatisfactory and possible reasons for this poor publication record are discussed. The need to increase research funding for biological sciences is also addressed. An overview of the present state of biological sciences research in the country is presented.
\end{abstract}

Key words: Biological sciences, National Science Foundation, publications, research grants.

\section{INTRODUCTION}

Early man developed a relatively detailed knowledge of the animals and plants in his surroundings, for his very survival depended on the accurate recognition of non-poisonous plants for consumption and medicinal use, as well as upon understanding the habits of dangerous animals This awareness enabled him to domesticate animals and develop stable and efficient agriculture to sustain large, settled communities. Therefore, in all probability interest in the biological sciences predates documented evidence of these interests. Traditionally, the term biology has meant the study of plants (botany) and animals (zoology). However, with advancing knowledge of plants and animals, biological sciences, in addition to the principal disciplines of botany and zoology have also come to encompass other disciplines, notably, biochemistry, microbiology, molecular biology, ecology and environmental studies.

The Ayurvedic system of medicine was probably present in the island from very early times. The original scientific basis of this system was quite empirical. One of the earliest books on medicinal plants compiled in Ceylon was 
Sarartha Sangrahaya. This was authored by King Buddhadasa (330-400 AD) of the Anuradhapura period. In Ceylon, much of the recorded interest in botany during the 16th and 17th centuries can be attributed to the enthusiasm generated by Portuguese and Dutch medical professionals in obtaining traditional knowledge on the medicinal properties of local plants. ${ }^{1-2}$ This is documented in the published work of these professionals who worked in the country since the 17th century. Paul Hermann, the chief physician at the Dutch Hospital in Colombo Fort from 1672-1679 was an avid botanist who later became the Professor of Botany at Leiden University in Holland. The collections of plants he sent to Holland formed the basis of a classification by Linnaeus, who established taxonomic biology as a discipline. Hermann also authored two books, Museum zeylanicum and Flora zeylanica, both on the flora of Ceylon. Foremost among 19th century botanists was Henry Trimen who in 1888 published Hortus zeylanicus as well as several papers on local flora in scientific journals. He is best remembered for his monumental work, Handbook to Flora of Ceylon. Among the pioneer zoologists was E.F. Kelaart, who in 1852 published Prodromes faunae zeynacae, a four part publication on mammals, birds, reptiles and amphibia of Ceylon. The other local scientific journals of the 19th century were the Journal of the Royal Asiatic Society (Ceylon branch) which also published several papers on mammals, birds and reptiles by Kelaart. The Ceylon Medical Journal, was first published in 1887 and beginning with the very first issue carried articles on Medicinal Plants of Ceylon. ${ }^{1}$ Spolia zeylanica was first published by the National Museum in 1904, with Arthur Willy as its first editor. The Ceylon Journal of Science (Biological Sciences) was also started in the early part of the century by the University.

It is very likely that much of this early work was driven by personal interest, and was dependent on the use of general institutional money or even private funds for research expenses. However, it is documented that some studies on projects of economic importance were specifically commissioned by the British colonial government. In 1854, the government promoted E.E. Celerywood who was the Naturalist to the Ceylon government, to study the life history of the pearl oyster. His recommendations for improving the ailing pearl fisheries industry were subsequently implemented by the government. Henry Trimen as Superintendent of the Royal Botanical Gardens, Peradeniya was responsible for salvaging the plantation industry by substituting tea for coffee which was, at that time, devastated by coffee blight. ${ }^{2}$

The establishment by the colonial government of the University College and institutes for research into the major export oriented crops as well as medical research were landmarks in introducing a research based environment supported by public funds to the country. Accordingly, the Medical Research Institute, Tea Research Institute, Coconut Research Institute and Rubber Research Institute carried out what could now be termed applied biological research that was funded from monies allocated from government revenue. Research in the 
University on the other hand was initially based on areas of personal interest. It was probably supported by general funds allocated to the University that were not specifically earmarked for research activities.

This article briefly traces the origins of modern biological sciences research in the country and attempts to evaluate the role of the National Science Foundation (NSF) and its predecessors in promoting research.

\section{FUNDING FOR RESEARCH IN BIOLOGICAL SCIENCES (NSF)}

The creation of research grant awarding bodies supported by public funds in the developed world i.e., the Medical, Agriculture and Science Research Councils in the United Kingdom, the National Science Foundation in the USA, and equivalent bodies in the bigger economies of Asia led to the demand for a similar body in Sri Lanka. Government support for biological science research in the country began with the establishment of the National Science Council (NSC) in 1968 to be followed by its successors, the Natural Resources, Energy and Science Authority (NARESA) in 1981 and more recently, in 1998, the National Science Foundation (NSF). The NSC/NARESA/NSF funds research in biological science through selection of research grant applications submitted to its Steering/Working Committee on Biological Sciences. The funding from NSC, NARESA and NSF has been pivotal in creating interest and providing opportunities for establishing biological sciences research in universities and other research organisations in the country which have not had external funding for research purposes.

The allocation of research funds for biological sciences research is made annually, and the numbers awarded are dependent on available funds as well as the number of grant applications. Applications are received in response to a general press advertisement by NSF that encompasses all areas of research covered by Steering/Working Committees. In addition, this information on research grants is also circulated to the universities and other relevant research institutes. The Steering/Working Committee examines each grant application individually and selected applications are ranked according to their scientific merit and also in accordance with the current research priorities set by the Committee. These priorities, formulated according to the research needs of the country, are reviewed periodically. Prospective grantees are interviewed, project proposals discussed and when necessary advised on possible improvements to proposed plans of research. Often researchers are appraised of other scientists working in the same areas of research interest within the country. This has been particularly beneficial to young researchers embarking on independent research.

In addition, specific priority areas were selected in 1998 and research commissioned to individual groups in these areas. Research on indigenous aquarium fish, restoration ecology, increasing dairy production and increasing rice yields 
through improved soil microbial activities were areas selected for soliciting commissioned research. However, the Steering/Working Committee was not successful in the sustained implementation of programmes in commissioned research that involved the participation and collaboration of scientists from several institutions.

During the past 30 years a sum of Rs. 11 million from government funds has been utilised for research in biological sciences. Two hundred and thirty one (231) research grants were awarded for this research between 1970 and 1997. Allocations for individual grants generally increased during this period (Figure 1a). However, this increase does not take into consideration the depreciation of the rupee or the increasing cost of equipment and supplies needed for modern biological research. Hence the increase in the average grant over the 30 year period is difficult to evaluate in real terms. Of the grants, 72 grants were awarded between 19701979, 102 grants in the period 1980-1989 and 44 projects supported during the period 1990-1997. (Figure 1b).

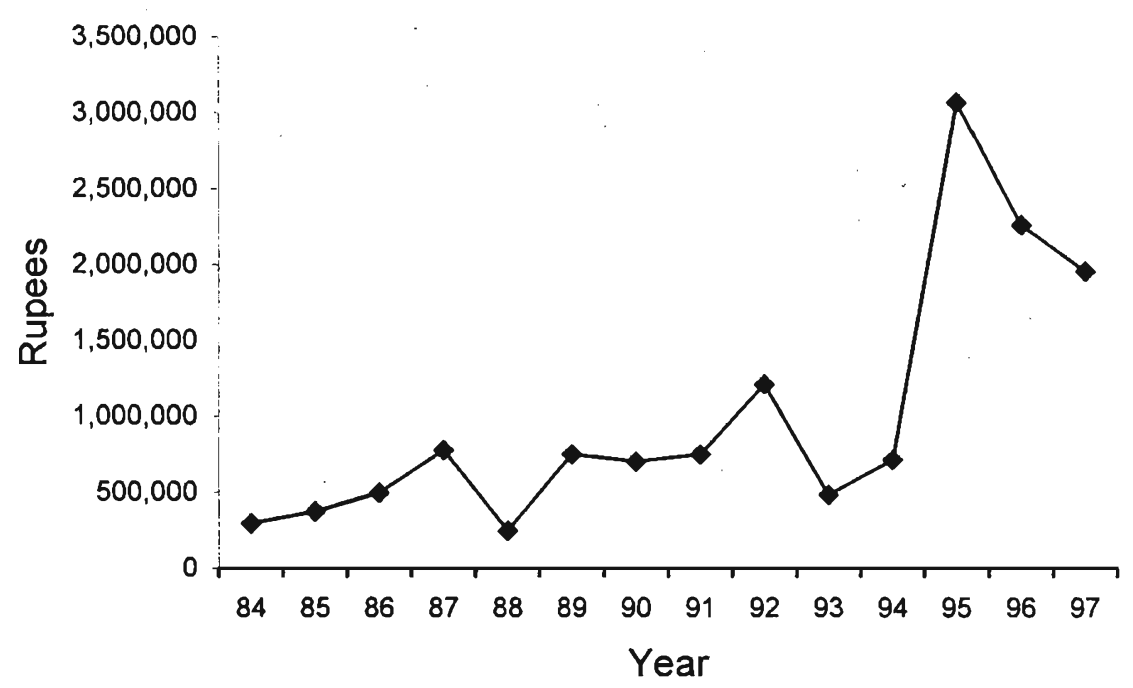

Figure 1a: Total funds allocated by NSF for biological sciences grants from 1984 to 1997 . 


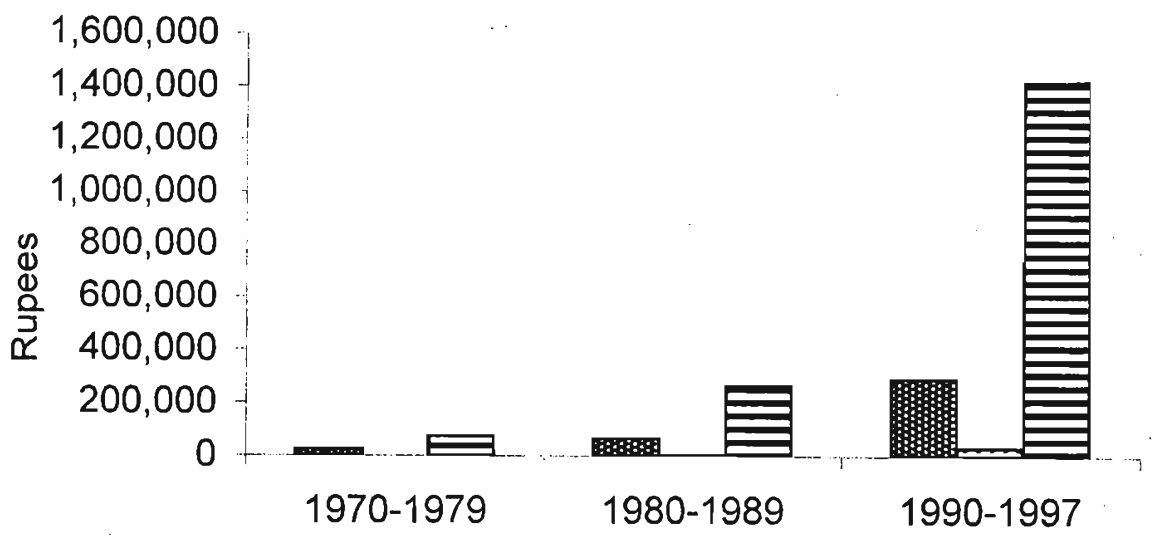

Average grant BLowest allocation BHighest allocation

Figure 1b: Changes in the value of NSF grants. for biological sciences over a period of three decades

Steering/Working Committees on biological sciences have endeavoured to distribute the funds equally among the principal disciplines of botany and zoology (Figure 2a). A recent trend has also been to encourage interdisciplinary research. In the plant sciences, the major research areas funded have been microbiology, economic plants and eco-taxonomy related to plant conservation (Figure $2 \mathrm{~b}$ ). In the animal sciences, major funding has been provided for research on insect pests and human disease vectors, ornamental and food fish and shellfish (Figure 2c). This reflects, to a large extent the research priorities that have guided NSC/NARESA/ NSF funded research over the past 30 years. Of the projects funded until the end of 1998, 40 grantees were still being supported, as on-going grants. The majority of projects which received funding were deemed by the committee as having been completed successfully; in this category were 205 grants i.e. $79 \%$ of the total awarded. Some grants $(18.5 \%)$ were terminated either due to unsatisfactory progress or at the request of the grantees. In a few instances, i.e., $2.4 \%$, the grant applications were withdrawn by the grantees, prior to the commencement of research. 


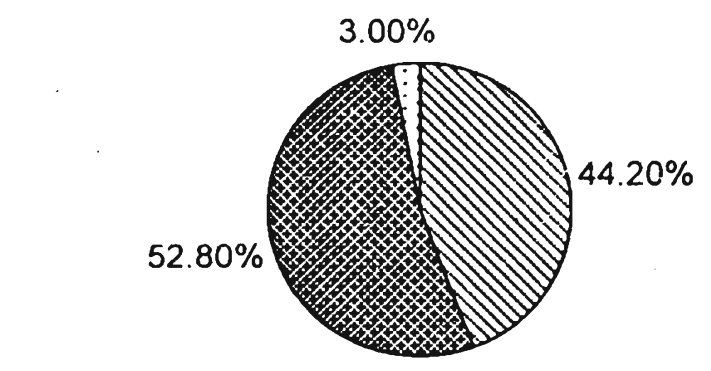

B Botany $\mathbb{Q}$ Zoology $\square$ Interdisciplinary

Figure 2a: The distribution of total of 231 grants between the principal disciplines of botany and zoology.

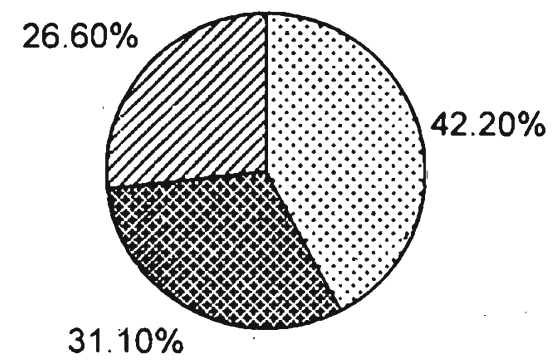

\section{DMicrobiology $\quad$ Economic plants Eco-taxonomy}

Figure 2b: The distibution of grants in botany between subdisciplines of microbiology, economic plants and eco-taxonomy.

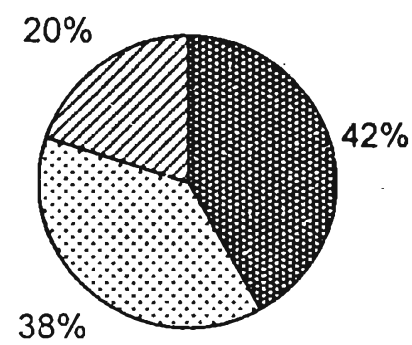

Insect pests and vectors

Figure 2c: The distribution of grants in zoology between subdisciplines of insect pest and human disease vectors, ornamental fish and shellfish. 
The Steering/Working Committee monitors the progress of the grantees through research reports submitted every six months during the tenure of the grant. In addition to ensuring that work is on course and on schedule, these reports provide an opportunity for grantees to discuss difficulties in carrying out research. Where necessary, grantees are invited to meet the members of the Steering/Working Committee for discussion. Project seminars are also held at regular intervals where not only the members of the Steering/Working Committee, but also other prominent scientists with interests in the relevant fields are invited to participate. The members of the Committee also carry out site visits to laboratories where it funds research. These activities have enabled NSF to provide a stimulus for improving the quality of publicly-funded research in the biological sciences. In the case of some young researchers, this activity has been an impetus for establishing research careers as well as providing guidance for research. Funding provided to more established researchers often includes provision to recruit a research assistant for the project. Since the establishment of the NSC and until the end of 1998, a total of 52 persons received training leading to the award of $48 \mathrm{M} . \mathrm{Sc} / \mathrm{M}$.Phil. degrees and $04 \mathrm{Ph} . \mathrm{D}$. degrees from Sri Lankan universities. It should be recorded that research supported by other Steering / Working Committees, notably, Medical and Veterinary Sciences, Biotechnology, Zoological Survey, Man and Biosphere and Agriculture have had a significant biological science component in them. This has also impacted on the development of biological sciences in the country.

The publication of research in good quality peer reviewed scientific journals (both international and national) is a measure of the quality of research carried out and its successful output. The Steering/Working Committees have emphasised this aspect of research and have encouraged grantees to publish their findings in journals. Regrettably however, such publications averaged $<0.5$ per grant awarded in biological sciences. It is noteworthy that publications in international and national journals were predominantly from a few notable research projects on insect pests and human disease vectors. Several grantees have presented their findings at scientific meetings both overseas and local, resulting in such work appearing as proceedings of conferences, meetings and workshops. In addition some monographs have also been published. Nevertheless conference communications cannot be considered as research publications in a strict sense since they are brief and nondescriptive and do not undergo the rigorous scrutiny of reviewers and editorial boards. However, grantees sometimes fail to inform NSF of publications after the final reports are submitted and this may well have resulted in the under representation of published papers. It should be recorded that the NSF annually collects information on the output of research projects and maintains a database of publications, but the success of this venture depends on the co-operation of grantees.

The majority of final reports submitted on the completion of research projects have been evaluated and accepted as submitted or accepted with minor corrections. A few grantees have been advised to carry out major revisions to the final reports 
but the outright rejection of final reports is not documented. Therefore, there appears to be no correlation between the acceptance of the final reports and the output of publications in refereed journals. This indicates that most grantees and also importantly the NSF Steering/Working Committee, have considered NSF funded research to be complete, merely on the submission of the final report and/or of a thesis by the research assistant. Several factors probably contribute to nonpublication of research. Research that lacks depth of analysis or of relatively trivial nature and considered to be of inferior quality will not often merit publication. Although most NSF funded research projects in biological sciences cannot be grouped in this category, the inability of grantees to critically assess and write up their own research for publication may well result in the work ending up as a mere final report. The lack of understanding of the importance of scientific writing and the existence of a scientific/academic culture that has failed to nurture scholarship in our research/teaching establishments also contribute to a poor publication record.

It is also possible that the NSF Steering/Working Committees on biological sciences have not, in the past, attached sufficient importance to good publications as a reliable measure of the successful outcome of the funded research programme, relying instead on the final reports of the grantees for this purpose. This issue may have to be carefully examined by the Committee.

\section{OTHER FUNDING FOR RESEARCH IN BIOLOGICAL SCIENCES}

At present besides NSF, several other agencies fund research in biological and related sciences in the country. The Council for Agricultural Research Policy (CARP) has financed research in agricultural biology, animal sciences, crop science, food science and technology, plant protection, soil microbiology, plant nutrition, post harvest technology etc. The McArthur Foundation, Swedish International Development Agency (SIDA), Swedish Agency for Research Co-operation with developing countries (SAREC), United Nations Environmental Programme (UNEP), Global Environmental Facility (GEF), Asian Development Bank (ADB), International Foundation for Science (IFS-Sweden), World Health Organisation (WHO), US Agency for International Development (USAID), The National Academy of Sciences (USA) through its Board on Science and Technology for International Development (BOSTID), The Wellcome Trust (UK), International Development Research Centre (IDRC), Japanese Agency for International Co-operation (JICA), International Atomic Energy Authority (IAEA), European Union (EU) etc., have either funded or are currently supporting biological sciences research in the universities and research institutes in the country. Much of this funding has been used initially for institutional strengthening, through building infrastructure and research capabilities. Laboratories have been equipped and several persons have received training overseas under these schemes. 
In keeping with their mandates, each funding agency has its own priorities for funding. As such, IFS-Sweden has supported research in aquaculture, animal production, crop science, forestry/agro-forestry, food science, natural products, molecular biology and rural technology, with research grants being given to younger researchers. UNEP and GEF currently support research in projects that would serve to improve the environment and protect biodiversity. SIDA, SAREC, WHO, USAID, BOSTID, Wellcome Trust and IAEA have supported research which spans the broad areas of biological, veterinary, medical and agricultural sciences. The International Union for Biosciences (IUBS) has supported the dissemination of knowledge and discussions in biotechnology, biological education, studies on biodiversity, taxonomy etc. through provision of facilities for local scientists to attend conferences and meetings held overseas.

\section{PRESENT STATUS OF RESEARCH}

Research in biological sciences is currently conducted in several institutes in Sri Lanka. The Tea, Rubber and Coconut Research Institutes are mandated to carry out research to upgrade their relevant industries. The Department of Agriculture and its affiliated research institutes e.g. the Rice Research Institute, Department of Minor Export Crops etc. are working in the broad areas of genetics and plant breeding, plant physiology and ecology, crop protection and entomology, tissue culture and post harvest technology. The recently established Plant Genetic Resources Centre has as its goal, the conservation and utilization of plant genetic resources of agricultural crops and some medicinal plants in Sri Lanka. Research for breeding and varietal development of fruits and vegetables is done at the Horticultural Research and Development Institute (HORDI). It is also a focal point for insect taxonomy. Research into the conservation and sustainable development of aquatic resources is the mandate of the National Aquatic Resources Agency (NARA). The Institute of Fundamental Studies which comes directly under the office of the President, is mandated to carry out basic scientific research and currently supports biological sciences research in Immunology, Molecular Entomology, Nitrogen Fixation, Plant Biotechnology and Limnology. Researchers at most Universities in Sri Lanka are engaged in research that falls broadly under the umbrella of Biological Sciences. The University of Colombo has very productive programmes on mammalian biology, ecology and molecular biology in the Department of Zoology, while the research in the Botany Department centres on ecology, conservation of biodiversity and tissue culture. The Department of Zoology at the University of Peradeniya has actively ongoing research programmes in entomology, vertebrate biology and ecology, while microbiology, plant ecology and post harvest technology are important areas of research at the Department of Botany. The Postgraduate Institute of Science (PGIS) was established in the University of Peradeniya in January, 1996. The principal objective of the PGIS is to promote and provide postgraduate education, training and research in science. The postgraduate research programmes in the faculty of science have been transfered to the PGIS which also conducts taught 
M.Sc. courses. The ten Boards of study at the PGIS include Biochemistry and Molecular Biology, Environmental Sciences, Plant Sciences and Zoological Sciences. Research into fisheries and microbiology are well established at the Zoology and Botany Departments at the University of Kelaniya and the University of Sri Jayewardenepura has a strong research programme which covers many areas of study into forestry, within the Department of Botany. Fisheries research is well established at the University of Ruhuna. The Departments of Botany and Zoology at the Open University of Sri Lanka carry out research in plant systematics, biodiversity, conservation and entomology. The University of Jaffna and the Eastern University, despite severe constraints, presently carry out significant research in biological sciences.

\section{CONSTRAINTS AND OUTLOOK}

The NSF participates in meetings with the private and state sectors to disseminate appropriate information and findings which could probably have an impact at a level outside the research laboratory. The Steering/Working Committee on biological sciences has also organised several seminars/workshops on topics of current biological interest to researchers and the private sector. The joint NARESA/ACIAR (Australian Centre for International Agriculture Research) research project executed at the Department of Zoology, University of Kelaniya was responsible for introducing a biological control agent for eradicating Salvinia from waterways. On successful completion of research sponsored by NARESA, further implementation was handed over to the Department of Agriculture, but unfortunately, the problem of Salvinia has resurfaced in the country, probably due to the breakdown of the eradication programme.

In Sri Lanka at present, the NSF is probably the largest supporter of biological sciences research, by way of the numbers and diversity of projects. However, an assessment of the research output in the biological sciences in Sri Lanka is not accurately reflected in the publication record of NSC/ NARESA/NSF supported research alone. Although the level of NSF funding has improved, it is still grossly inadequate to comfortably meet the real needs in biological research. The escalating cost of research, the non-availability of many important journals and the comparatively low funding available has imposed constraints on scientists. Competitive research of high quality is often multifaceted and multidisciplinary and requires more funding than is available through the NSF. Therefore, NSF grantees engaged in such research often already have, or need to seek, funds from other agencies as well, if research of good quality is to be carried out. Proof of this lies in the acknowledgement of funding by other agencies and the NSF in publications. 
The low level of funding also demoralises young researchers many of whom have returned to the country with high expectations for continuing their research after obtaining postgraduate qualifications. Often the lack of proper infrastructure and other facilities as well as the bureaucracy in their home institutions do not permit them to pursue research on the lines that they received their training. Often young grantees who continue to carry out good quality research in the country are those able to maintain links with their mentors overseas and obtain funds through them, in order to establish careers in research in this country. When this or other sources of funding are not available, researchers are compelled to carry out more mundane research. This can contribute to the increasing number of requests for funding survey type of research, which will invariably lack enthusiasm and depth. In the present scenario, the ultimate consequence is that such projects often become another statistic for NSF funding but without the required output of originality, quality findings and publications.

Along with the need for increasing the amount of research funding, there is also probably a need for improving co-ordination in evaluating and selecting grants between the different NSF Committees that have an impact on biological sciences research. Similarly, better co-ordination between different granting bodies in the country, such as CARP and the NSF may also lead to more productive utilization of funds. In assessing the current value of research grants, the effect of inflation and rupee depreciation has to be taken into consideration. In general, the grants awarded by overseas funding agencies are much larger than NSF grants. Such grants are becoming extremely difficult to obtain, due to intense competition, financial cutbacks and stringent requirements of the granting bodies. However, a few local researchers have been successful in obtaining these funds and carry out research in biological sciences independent of support from the NSF; they also publish their research in good scientific journals. Present day science invariably requires competitive funding from agencies other than the NSF and overseas collaboration; the need to sometimes carry out specialised aspects of research in collaborating laboratories overseas is also common place. Unfortunately the NSF does not fund grantees to do experimental work overseas. In this context, existing restrictions on the recognition of work by grantees who have successfully competed for additional non-NSF funding need to be carefully re-examined.

The success of established research groups has been the ability to sustain good quality research with continued publications in peer reviewed journals. These publications do not come easily in the biological sciences and overseas funding agencies and collaborators often value quality research. It is imperative that researchers endeavour to carry out well planned and executed research, for in such circumstances, the generation of quality publications does not become a burden to the researcher. 
Despite its limitations, NSF funding has been crucial in establishing and maintaining research in biological sciences across a broad cross section of institutions in Sri Lanka. The research training opportunities provided by the NSF (through M.Phil and Ph.D degrees awarded) can be considered a contribution to the training of junior scientists in the country. But, the real contribution to (scientific) human resource development would be if these trained persons continued to serve in scientific/academic establishments. However, there has not been a follow up on the careers pursued by NSF sponsored M.Phils and $\mathrm{Ph}$.Ds after obtaining these postgraduate qualifications. Given the probable future constraints for large scale funding of new projects and the low measurable research output of most completed projects in the biological sciences, the NSF Working Committee perhaps needs to re-evaluate the criteria for disbursing research funds, encouraging quality and competitive research. The need for quality research must take precedence over narrow demarcations of compartmentalised research which requires relatively small allocations through NSF grants. Quality research and publications are important not only for scientists involved in full time research, but also for university teachers, for critical scientific thinking and new knowledge are best conveyed to students only by persons committed to advancing the frontiers of knowledge.

\section{References}

1. Senadhira A. (1995). History of scientific literature of Sri Lanka. Foremost Productions Ltd. Colombo.

2. Uragoda C.G. (1993). Some doctors celebrated for their non-medical achievements. A. C. E. Koch memorial lecture, Physiological Society of Sri Lanka. 